Article

\title{
Estimating Winter Annual Biomass in the Sonoran and Mojave Deserts with Satellite- and Ground-Based Observations
}

\author{
Grant M. Casady ${ }^{1, *}$, Willem J.D. van Leeuwen ${ }^{2,3}$ and Bradley C. Reed ${ }^{4}$ \\ 1 Department of Biology, Whitworth University, Spokane, WA 99251, USA \\ 2 School of Natural Resources and the Environment, University of Arizona, Tucson, AZ 85721, \\ USA; E-Mail: leeuw@cals.arizona.edu \\ 3 School of Geography and Development, University of Arizona, Tucson, AZ 85721, USA \\ 4 Climate and Land Use Change, United States Geological Survey USGS), Reston, VA 20192, USA; \\ E-Mail: reed@usgs.gov
}

* Author to whom correspondence should be addressed; E-Mail: gcasady@whitworth.edu; Tel.: +1-509-777-4597; Fax: +1-509-777-3454.

Received: 22 December 2012; in revised form: 16 February 2013 / Accepted: 16 February 2013 / Published: 22 February 2013

\begin{abstract}
Winter annual plants in southwestern North America influence fire regimes, provide forage, and help prevent erosion. Exotic annuals may also threaten native species. Monitoring winter annuals is difficult because of their ephemeral nature, making the development of a satellite monitoring tool valuable. We mapped winter annual aboveground biomass in the Desert Southwest from satellite observations, evaluating 18 algorithms using time-series vegetation indices (VI). Field-based biomass estimates were used to calibrate and evaluate each algorithm. Winter annual biomass was best estimated by calculating a base VI across the period of record and subtracting it from the peak VI for each winter season $\left(\mathrm{R}^{2}=0.92\right)$. The normalized difference vegetation index (NDVI) derived from 8-day reflectance data provided the best estimate of winter annual biomass. It is important to account for the timing of peak vegetation when relating field-based estimates to satellite VI data, since post-peak field estimates may indicate senescent biomass which is inaccurately represented by VI-based estimates. Images generated from the best-performing algorithm show both spatial and temporal variation in winter annual biomass. Efforts to manage this variable resource would be enhanced by a tool that allows the monitoring of changes in winter annual resources over time.
\end{abstract}

Keywords: invasive species; MODIS; NDVI; monitoring; vegetation index 


\section{Introduction}

Cool season ephemeral plants (winter annuals) play an important role in Mojave and Sonoran desert ecosystems of southwestern North America. Winter annuals provide forage for livestock and native wildlife [1,2], influence the region's fire regime [3-5] and affect rates of wind- and water-induced soil erosion [6]. Invasive winter annuals predominate in some areas, especially in areas of disturbance [7]. This predominance of alien species results in changes to the structure and function of desert ecosystems, perhaps most dramatically by influencing fire regimes [4].

Winter annual abundance and productivity are highly variable from year to year, and are influenced by such factors as climate, alien species, off road vehicle use, and grazing regimes [8]. Of these factors, climate is the largest determinant [9]. Winter annual abundance and productivity is often associated with increased precipitation following winter frontal storm systems and El Niño, although the link between these is not strong [9].

Landscape scale estimates of winter annual abundance and productivity are required to evaluate the impact of winter annuals on wildfire risk, endangered species and soil erosion. Such information also enables evaluation of the relationships between changes in climate and winter annual production. Quantitative approaches to the monitoring of winter annual abundance at the landscape scale are few. Winter annual production is often subjectively categorized as poor, good, or great, in order to describe displays of flowering native winter annual plants. Bowers [9] successfully related such qualitative measures with herbaria records in order to attain a more quantitative measure of winter annual abundance, however these qualitative measures are not systematically recorded, nor do they provide a spatially explicit representation of winter annuals.

Given the value of assessing winter annual biomass over large areas, and the unpredictable and ephemeral nature of winter annual growth, an objective and consistent method for the spatially explicit monitoring of winter annuals is needed. Remote sensing often provides an effective tool for measuring vegetation over large areas; however the measurement of winter annuals in arid regions presents unique challenges. Winter annuals respond opportunistically to precipitation events, and constitute a variable fraction of ground cover against a matrix of spatially varying soil backgrounds. The use of multi-temporal satellite data for measuring inter-annual changes in vegetation patterns in semi-arid rangeland environments is common, e.g., [10-12], however the selection of appropriate dates for image acquisition is problematic given the ephemeral nature of winter annuals in the southwest.

Vegetation indices (VI) have often been used to estimate vegetation greenness [13-15], and the recent availability of a well calibrated time-series of satellite data has provided a valuable tool for monitoring seasonal changes in vegetation without requiring the selection of individual image acquisition dates $[16,17]$. The high temporal frequency of data collected by the Moderate Resolution Imaging Spectroradiometer (MODIS) allows for the monitoring of vegetation growth across seasons, allowing the observation of winter annual growth without the need to target a specific date of observation, as with data of lower temporal frequency. Wallace and Thomas [18] have successfully used MODIS data to estimate winter annual cover for a site at the Mojave National Preserve. Their

work compared field-based estimates of fractional vegetation cover to MODIS Enhanced Vegetation Index (EVI) data over the winter season. They found that the relationship between MODIS EVI data and cover estimates was best when data from 2002, a record dry year at the Mojave National Preserve, 
was subtracted from the current year. We extend this work by developing and testing a metric that uses a similar rationale, but is broadly applicable across the semi-arid ecosystems in both the Sonoran and Mojave Deserts.

This prior work indicates that MODIS provides a well characterized, consistent time-series of data, making it a good sensor for evaluation as a tool to assess winter annual biomass. There are, however, three research questions that should be addressed to specify the best approach to the use of these data.

1. Does EVI or the Normalized Difference Vegetation Index (NDVI) provide the best assessment of winter annual biomass? The MODIS VI product is calculated for both EVI and NDVI; our research evaluated the relative value of both indices for predicting winter annual biomass.

2. Is there a standardized approach to selecting comparison dates for assessing relative winter annual biomass that will perform better than a simple VI measure across large areas? Wallace and Thomas [18] found in their study that they were able to assess winter annual cover best when the current years' data were compared to 2002, a record dry year in their study area. Here we evaluated two methods for selecting comparison dates for each pixel from the time-series independent of location, since dry periods are likely to vary from location to location.

3. Is the time step of the dataset important? Because winter annual vegetation can emerge and senesce in a short time period, the temporal resolution of the time-series may be an important consideration for the use of satellite data to evaluate winter annual biomass. We evaluated both 8- and 16-day composites of MODIS VI data in order to determine the relative importance of temporal resolution.

\section{Methods}

\subsection{Field Areas}

Data for the calibration and validation of remotely sensed estimates of winter annual biomass were collected from four areas in the Sonoran Desert and one area in the Mojave Desert (Figure 1). While all of these areas represented semi-arid environments, they varied in the amount and timing of precipitation and the temperature ranges experienced, and consequently the vegetation typical of each area. The characteristics of the five areas are summarized in Table 1, and described below.

The Sonoran Desert National Monument (SDNM) is the most arid of the areas sampled. Dominant trees at the sites are palo verde (Parkinsonia microphylla Torr.), ironwood (Olneya tesota A. Gray), and mesquite (Prosopis velutina Woot.). Creosote (Larrea tridentata Coville) is the primary shrub, with triangle leaf bursage (Ambrosia deltoidea (Torr.) Payne) as a common subshrub. The area has few perennial grasses. Winter annual plants are dominated by filaree (Erodium cicutarium (L.) L'Her. ex Aiton) and Phacelia spp.

The Ironwood Forest National Monument (IFNM) has similar vegetation composition to the Sonoran Desert National Monument, although creosote is less common, and palo verde is more common. Despite having slightly higher average winter precipitation than the SDNM area, this area had the lowest winter annual production of the areas we measured. 
Figure 1. Map of the five study areas (shown as diamonds) used to take field based estimates of winter annual biomass. Study areas consisted of Joshua Tree National Park in the Mojave Desert, Sonoran Desert National Monument, Ironwood Forest National Monument, and Catalina State Park in the Sonoran Desert, and Agua Fria National Monument along the ecotone between the Sonoran Desert and the Mogollon Rim.

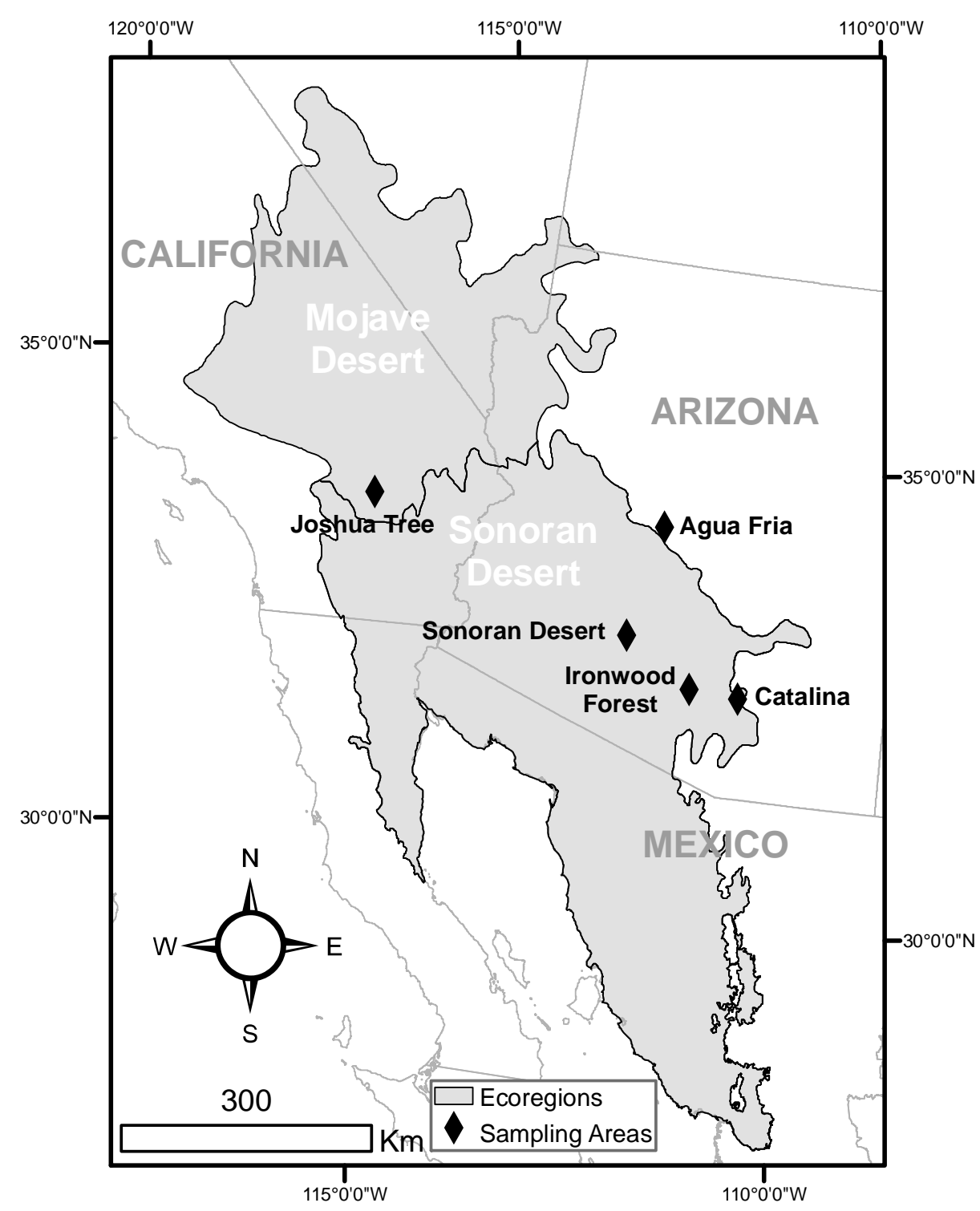

Catalina State Park (CSP) is the eastern most of the five study areas, and experiences the lowest winter precipitation as a percentage of annual precipitation (40\%). Higher elevation in this area than at SDNM and IFNM is likely responsible for higher overall precipitation and evapotranspiration. Of the areas surveyed, this has the highest diversity of species, both perennial and annual. Dominant tree species are palo verde and mesquite. Triangle leaf bursage and brittlebush (Encelia farinosa A. Gray ex Torr.) are common subshrubs, and a suite of perennial grasses is present, including tanglehead (Heteropogon contortus (L.) P. Beauv ex Roem. \& Schult.), purple threeawn (Aristida purpurea Nutt.), and buffelgrass (Pennisetum ciliare (L.) Link). Winter annual diversity is also high, including 
many native species such as Lupine spp., Amsinckia spp., and Phacelia spp., as well as alien species such as filaree and red brome (Bromus rubens L.).

Table 1. Description of the five study areas used in the collection of cover and height estimates for the calibration and evaluation of remotely sensed estimates of winter annual biomass, including the number of sample sites used to estimate winter annual biomass across each of the areas.

\begin{tabular}{|c|c|c|c|c|c|}
\hline Area & $\begin{array}{c}\text { Location } \\
\text { (Lat, Long) }\end{array}$ & $\begin{array}{c}\text { Elevation } \\
(\mathrm{m})\end{array}$ & $\begin{array}{l}\text { Winter Temp } \\
\text { (C) }\end{array}$ & $\begin{array}{l}\text { Precipitation (cm) } \\
\text { (Winter/Summer) }\end{array}$ & $\begin{array}{c}\text { Sample } \\
\text { Sites } \\
\end{array}$ \\
\hline $\begin{array}{c}\text { Sonoran Desert } \\
\text { National Monument }\end{array}$ & $\begin{array}{c}32.4 \\
-110.9\end{array}$ & $350-630$ & $7.3-22.5$ & $10.7 / 6.9$ & 6 \\
\hline $\begin{array}{l}\text { Ironwood Forest } \\
\text { National Monument }\end{array}$ & $\begin{array}{l}34.2 \\
-112.1\end{array}$ & $630-760$ & $7.0-23.0$ & $10.6 / 13.0$ & 6 \\
\hline Catalina State Park & $\begin{array}{c}32.8 \\
-112.3\end{array}$ & $1,000-1,100$ & $5.7-20.9$ & $12.1 / 17.7$ & 6 \\
\hline $\begin{array}{l}\text { Agua Fria National } \\
\text { Monument }\end{array}$ & $\begin{array}{c}32.4 \\
-111.5\end{array}$ & $830-930$ & $4.8-19.1$ & $19.7 / 12.9$ & 7 \\
\hline $\begin{array}{c}\text { Joshua Tree National } \\
\text { Park }\end{array}$ & $\begin{array}{c}34.0 \\
-116.0 \\
\end{array}$ & $530-1,470$ & $3.8-17.5$ & $14.6 / 3.7$ & 12 \\
\hline
\end{tabular}

Agua Fria National Monument (AFNM) is the most mesic of the areas surveyed, and is located along the ecotone between the Sonoran Desert and the Mogollon Rim, an area of steep elevational gradient, with associated changes in temperature, precipitation, and evapotranspiration. All of the sites measured at the AFNM were burned in the Cave Creek fire in 2005. The site has very few woody plants, mostly mesquite, and the dominant perennial grass is tobosagrass (Pleuraphis mutica Buckley). The site is heavily dominated by invasive winter annual grasses, including red brome, mouse barley (Hordeum murinum L.), and wild oat (Avena fatua L.).

Joshua Tree National Park is unique among the areas surveyed because it includes the only sites located within the Mojave Desert. Sites in the Mojave are dominated by Yucca spp. (including Joshua trees), juniper (Juniperus californica Carrière), four wing saltbush (Atriplex canescens (Pursh.) Nutt.), and creosote. Big galletagrass (Pleuraphis rigida Thurb.) is found as a dominant perennial grass, and annual grasses are represented by both red brome and cheatgrass (Bromus tectorum L.). Annual forbs include Amsinkia spp. and the invasive Sahara mustard (Brassica tournefortii Gouan).

\subsection{Field Data}

Field data were collected at sample sites in each of the five study areas such that they represented a range of winter annual biomass across each area as determined by an initial evaluation of MODIS NDVI data from the winter of 2007-2008. Sampling sites were selected such that they could be considered as independent samples by selecting sites that were either distant from one another $(>2 \mathrm{~km})$ or vegetatively dissimilar, as assessed using aerial photographs and site visits. In all cases sites were separated by at least $250 \mathrm{~m}$. A total of 41 sites were sampled from 3 February through 4 April 2009. Ten of these sites were sampled twice (once early and once late), resulting in a total of 51 estimates of biomass across the five study areas. At each site estimates of cover and vegetation height were taken 
such that they described conditions across an area the size of a MODIS $250 \mathrm{~m}$ pixel. Pixel dimensions of MODIS $250 \mathrm{~m}$ data are actually resampled to approximately $231.67 \mathrm{~m}$. Sample sites therefore measured 231 by $231 \mathrm{~m}$. Cover and height were assessed for $200.5 \times 0.5 \mathrm{~m}$ plots across each sample site, arranged randomly along four transects evenly spaced across the site. Cover was assessed by ocular estimation of the projected cover of winter annual plants as a percentage of a $0.5 \times 0.5 \mathrm{~m}$ plot. Vegetation height was assessed as the estimated average height of all winter annual plants within the plot by measuring the median individual with a metric ruler.

Transects were spaced approximately every $77 \mathrm{~m}$, and plots were arranged beginning at a random point between 1 and $31 \mathrm{~m}$ along each transect and measured systematically every $50 \mathrm{~m}$ along the transect. Between two and four (most often three) of the 0.5 by $0.5 \mathrm{~m}$ plots were selected at each of the sites for clipping. All annual vegetation was clipped at $0.5 \mathrm{~cm}$ above ground level to develop relationships between cover, height estimates, and aboveground biomass in a double sampling approach [19]. Samples were dried in an oven at $60{ }^{\circ} \mathrm{C}$ to a constant weight and weighed to determine the dry weight of annual biomass. These data were then used to relate cover and height to biomass for all estimated plots. Because of heteroscedasticity in residuals for the untransformed response, the response was transformed using the natural log, resulting in a model of the form

$$
\ln (\text { biomass })=\beta_{0}+\beta_{1} \text { cover }+\beta_{2} \text { height }+\varepsilon
$$

where $\ln$ (biomass) is the natural log of the dry weight in grams of biomass clipped from each sample plot, and cover and height are the percent cover and height in centimeters, respectively, for the associated sample plots. Equation (1) was used to determine appropriate coefficients $\left(\beta_{0}, \beta_{1}\right.$ and $\beta_{2}$ and $\varepsilon$ the error term) for the estimation of biomass from height and cover estimates.

\subsection{Remote Sensing Data}

Remote sensing based estimates of biomass were established using time-series of two vegetation index products derived from data collected by the Terra-based MODIS. Collection five MODIS data acquired from the USGS Land Processes Distributed Active Archive Center (LP DAAC, https://lpdaac.usgs.gov/) were used to create a time-series for both products covering the period from March 2000 through April 2009. The first product was the $250 \mathrm{~m}$ vegetation index product, MOD13Q1, which includes both NDVI and EVI datasets composited over a 16-day period, resulting in 23 16-day periods per year. NDVI is calculated as

$$
\text { NDVI }=\rho N I R-\rho \operatorname{Red} / \rho N I R+\rho \operatorname{Red}
$$

where $\rho$ NIR and $\rho$ Red indicate near infrared $(841-876 \mathrm{~nm})$ and red $(620-670 \mathrm{~nm})$ reflectances, respectively. EVI is altered to account for soil background and atmospheric influences as

$$
\mathrm{EVI}=\mathrm{G} \times(\rho \mathrm{NIR}-\rho \mathrm{Red}) /\left(\rho \mathrm{NIR}+\mathrm{C}_{1} \times \rho \mathrm{Red}-\mathrm{C}_{2} \times \rho \text { Blue }+\mathrm{L}\right)
$$

where $\rho$ NIR, $\rho$ Red, and $\rho$ Blue $(459-479 \mathrm{~nm})$ are reflectances, $C_{1}$ and $C_{2}$ are atmospheric correction coefficients for the Red and Blue band respectively, $\mathrm{L}$ is the soil background adjustment coefficient, and $\mathrm{G}$ is a gain factor. MOD13Q1 EVI coefficient values are $\mathrm{G}=2.5, \mathrm{C}_{1}=6, \mathrm{C}_{2}=7.5$, and $\mathrm{L}=1$. The compositing algorithm for these data selects pixels for use in vegetation indices by selecting optimal observations with minimum view angle and maximum VI value across the 16-days of each period [20]. 
The second product used was the $250 \mathrm{~m}$ reflectance data, MOD09Q1, which includes the two $250 \mathrm{~m}$ reflectance bands, red and near infrared (NIR), composited over an 8-day period, resulting in 46 8-day periods per year. Reflectance data are composited according to minimal aerosol loading, view angle, high observational coverage, and minimum $500 \mathrm{~m}$ blue channel value, using the daily atmospherically corrected MOD09 data as input [21]. We then used Red and NIR data to calculate NDVI from the MOD09Q1 data. Since the MOD09Q1 product does not include the blue band (MODIS uses a $500 \mathrm{~m}$ blue band available as a composited reflectance product-MOD09A1) we were unable to calculate EVI from the $250 \mathrm{~m}$ reflectance data. The use of these two products (MOD13Q1 and MOD09Q1) provided a comparison between higher observational frequency available with the MOD09Q1 data, and the compositing algorithm optimized for use with vegetation indices provided by the MOD13Q1 product, as well as the availability of the EVI product from MOD13Q1.

\subsection{Vegetation Index Processing}

We compared three techniques for determining the appropriate VI value for use in the estimation of winter annual biomass. All three of these techniques relied on the time-series of vegetation data to select an appropriate date for comparison to the field data collected. Figure 2 illustrates the three methods applied to a single pixel. Prior to applying the three techniques, the data were filtered for clouds using the quality data available for the MOD09 and MOD13 datasets. Subsequently cloudy data were removed and replaced with an average of the values of that pixel from data of the most proximate cloud free time periods before and after the target period. The data were then smoothed using a Savitzky-Golay filter as described in Jönsson and Eklundh [22] to remove noise in the time-series due to atmospheric effects on the data.

The first technique we evaluated was the vegetation index with no adjustments except for the initial smoothing $\left(\mathrm{VI}_{0}\right)$. Among the three techniques, this approach can be considered as neither spatially, nor temporally contextual. VIs can be heavily influenced by the spectral characteristics of the soil background, and by the structure of persistent woody vegetation in the pixel, such that comparison of VIs between pixels with different soil backgrounds or vegetation structure is challenging [23].

The second approach $\left(\mathrm{VI}_{10}\right)$ therefore accounted for each pixel's background VI value. This was done by calculating the value of the lowest 10th percentile of all the data for each pixel across the entire time-series. In this way the VI value for the pixel at a time when it had a minimal amount of vegetation was determined. We chose not to use the absolute minimum value given the potential for low values to be an artifact of noise in the time-series associated with atmospheric contamination. The use of the 10th percentile as a minimum is somewhat arbitrary, and assumes that no more than ten percent of the data are subject to this noise. This is a relatively conservative value, and the exact percentile used is not critical if it sufficiently accounts for this noise. Our goal was to achieve a relatively low percentile that could be used as a base line across a number of land cover types. Winter annual growth was then assessed as an increase in VI above the 10th percentile value for each pixel during the winter or early spring months (November through April). This second approach can be expected to work well if there are not other increases in vegetation occurring during the growth of winter annual plants. If perennial plants are growing during this time the VI value would be higher than expected from winter annuals alone. 
Figure 2. A portion of the smoothed EVI time-series (2007-2008) is shown to illustrate the three methods investigated for the determination of peak winter annual production in the winter of 2008-2009 for a single pixel. All three methods identify the peak of the VI in the 2008-2009 winter season (grayed area) and subtract it from a base value, as shown by the labeled brackets for each of the tree techniques. For $\mathrm{VI}_{0}$ the base value is 0 , making the $\mathrm{VI}_{0}$ value equal to the smoothed EVI. For $\mathrm{VI}_{10}$ the baseline is the tenth percentile for the entire period of record from 2000 to 2009 , shown as a straight dashed line, the $\mathrm{VI}_{10}$ measure therefore being equal to the difference between the smoothed EVI and the value of the tenth percentile for that pixel over the period of record. For $\mathrm{VI}_{\mathrm{MED}}$ the baseline is represented by the repeating dotted line, and is the calculated as the median value for each period across all years, and $\mathrm{VI}_{\mathrm{MED}}$ calculated as the difference between the current period and the median of the period for all years.

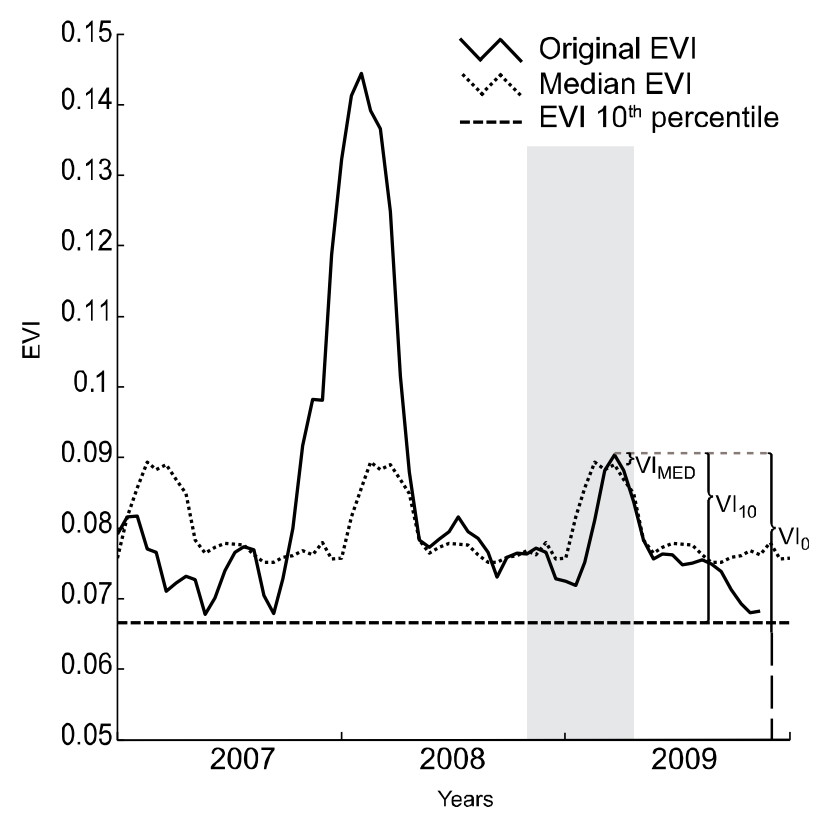

The third approach $\left(\mathrm{VI}_{\mathrm{Med}}\right)$ attempts to adjust for the possibility of perennial plant growth during the winter season by accounting for a pixel's value at the particular period of observation, across all years. This was done by calculating the median value for each period across all years, then comparing the value of the VI in that period for the current year to the median across all years. While this approach may separate non-annual winter growth from winter annuals, it may also include commonly occurring winter annuals in the calculation of the base median, thereby underestimating the measure of total winter annual biomass.

\subsection{Relating VI Data to Field Data}

The techniques described above resulted in a total of 18 relationships to be evaluated, including three techniques, to be applied using 8-day NDVI, 16-day NDVI and 16-day EVI, each either accounting for or not accounting for post-peak field measurements. Polynomial and exponential models were evaluated for their value in describing the 18 relationships, but did not provide 
substantial, consistent improvements over simple linear regression. Therefore, each of the 18 relationships was evaluated using the simple linear regression model:

$$
\text { biomass }=\beta_{0}+\beta_{1} \mathrm{VI}+\varepsilon
$$

where VI indicates one of the 18 methods discussed above, and biomass refers to the field-based biomass estimates. The Root Mean Squared Error (RMSE) and the coefficient of determination $\left(\mathrm{R}^{2}\right)$ were calculated for each model to give an indication of the goodness of fit. RMSE was calculated by performing a ten-fold cross-validation technique whereby one tenth of the data are iteratively left out of the RMSE calculation for ten iterations and the average of the ten RMSE values is reported. $\mathrm{R}^{2}$ was calculated as the fit of all data to each model.

\subsection{Generation of Winter Annual Biomass Images}

After the selection of the best model from among the 18 was made, this model was used to generate images for each of the study areas for each winter season from 2000-2001 through 2008-2009. These images were evaluated visually for their usefulness in indicating spatial and temporal variations in winter annual biomass for each of the study areas.

\section{Results}

\subsection{Biomass Estimates}

Double sampling for the estimation of kilograms of winter annual biomass per hectare given cover and height from selected field plots resulted in the equation

$$
\ln (\text { biomass })=0.5964+0.0329(\text { cover })+0.0353 \text { (height })+\varepsilon
$$

The $\mathrm{R}^{2}$ value for this relationship was 0.699 , based on a total of 137 measures of biomass taken across all sites, with an RMSE of $0.633 \mathrm{~g}$ per $0.25 \mathrm{~m}^{2}$ plot, equating to $25.32 \mathrm{~kg} / \mathrm{ha}$.

\subsection{Model Comparisons}

$\mathrm{R}^{2}$ values for most models were relatively high, ranging from 0.500 to 0.924 when considering data from all field sites. Cross validated RMSE values for the 18 models compared ranged from $42.80 \mathrm{~kg} / \mathrm{ha}$ to $152.10 \mathrm{~kg} /$ ha (Figure 3). Of the 18 models tested, the $\mathrm{NDVI}_{10}$ method using the 8-day composite of MOD09Q1 data after adjusting for field data collected after peak greenness provided the best estimate of winter annual biomass (Table 2, Figure 4). This model has an RMSE of $42.8 \mathrm{~kg} / \mathrm{ha}$, which is an improvement of $3.85 \mathrm{~kg} / \mathrm{ha}(9.0 \%)$ over the next best model (MOD13 NDVI 10$)$. This RMSE represents an error of between $4.7 \%$ to $53.7 \%$ of the range of above ground biomass measured in the field plots across all sites (79.6-609.2 kg/ha). 
Figure 3. RMSE values are shown for the 18 models tested using (A) all study areas and (B) excluding the Agua Fria study area. Data are grouped by VI data type, and within each data type the techniques are ordered such that the first three bars in each group (white) indicate methods without adjusting for post-peak data collection, and the next three (gray) indicate models after adjusting for post-peak collection dates. $\mathrm{N}=51$.

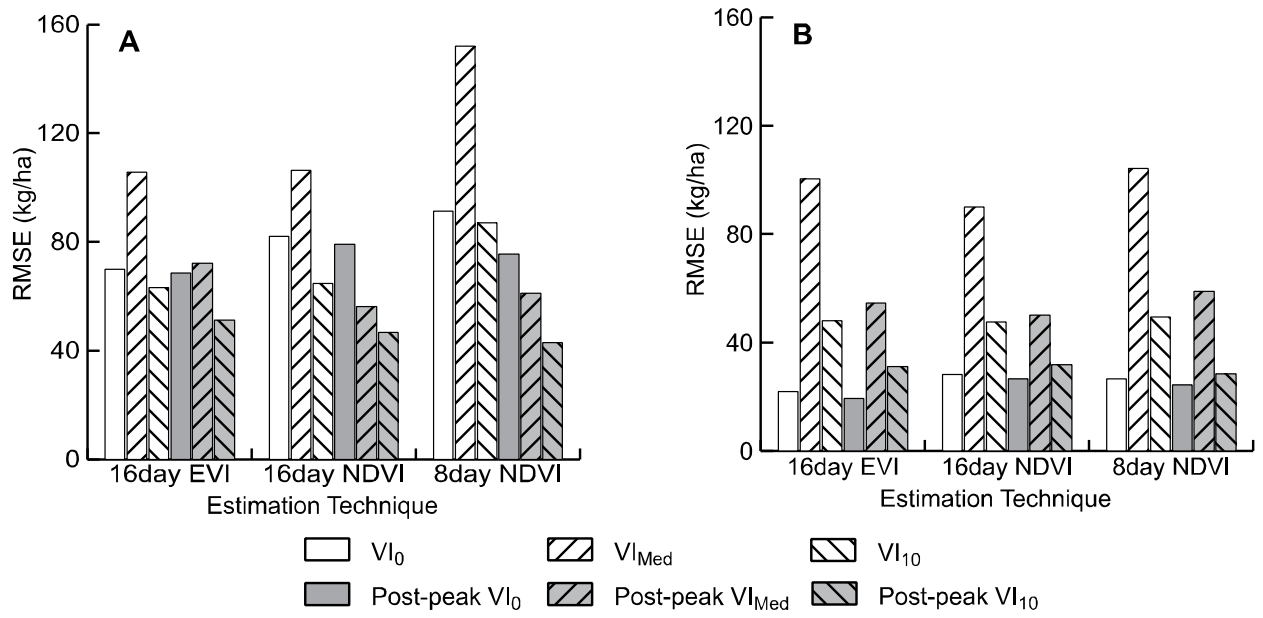

Table 2. Goodness of fit statistics for the 18 models compared in order to determine the best method of predicting winter annual biomass from MODIS time-series data. The first set of parameters are calculated using all five field sites, and the second are calculated excluding the Agua Fria site, which was the most productive of the five sites. Bolded models indicate goodness of fit metrics for models providing the best fit, as discussed in the text.

\begin{tabular}{|c|c|c|c|c|}
\hline \multirow[b]{2}{*}{ Model } & \multicolumn{2}{|c|}{ All Sites } & \multicolumn{2}{|c|}{ Excluding Agua Fria } \\
\hline & $\mathbf{R}^{2}$ & RMSE (kg/ha) & $\mathbf{R}^{2}$ & RMSE (kg/ha) \\
\hline MOD13Q1 EVI 0 & 0.882 & 69.96 & 0.155 & 21.98 \\
\hline MOD13Q1 EVI $\mathrm{Med}_{\mathrm{M}}$ & 0.831 & 105.60 & 0.000 & 100.27 \\
\hline MOD13Q1 EVI 10 & 0.881 & 63.26 & 0.051 & 47.98 \\
\hline MOD13Q1 EVI 0 peak & 0.913 & 68.63 & 0.252 & 19.51 \\
\hline MOD13Q1 EVI Med $_{\text {peak }}$ & 0.915 & 72.11 & 0.045 & 54.51 \\
\hline MOD13Q1 EVI 10 peak & 0.917 & 51.12 & 0.147 & 31.19 \\
\hline $\mathrm{MOD}_{13 Q 1} \mathrm{NDVI}_{0}$ & 0.788 & 82.12 & 0.040 & 28.29 \\
\hline MOD13Q1 NDVI ${ }_{\mathrm{Med}}$ & 0.742 & 106.38 & 0.070 & 90.03 \\
\hline $\mathrm{MOD13Q1} \mathrm{NDVI}_{10}$ & 0.833 & 64.67 & 0.000 & 47.61 \\
\hline MOD13Q1 NDVI 0 peak & 0.830 & 79.08 & 0.078 & 26.67 \\
\hline MOD13Q1 NDVI $_{\text {Med }}$ peak & 0.913 & 56.28 & 0.023 & 50.00 \\
\hline MOD13Q1 NDVI ${ }_{10}$ peak & 0.900 & 46.65 & 0.035 & 31.75 \\
\hline $\mathrm{MOD09Q1} \mathrm{NDVI}_{0}$ & 0.680 & 91.32 & 0.097 & 26.72 \\
\hline MOD09Q1 NDVI ${ }_{\mathrm{Med}}$ & 0.500 & 152.10 & 0.004 & 104.20 \\
\hline MOD09Q1 NDVI 10 & 0.706 & 87.05 & 0.023 & 49.33 \\
\hline MOD09Q1 NDVI 0 peak & 0.862 & 75.58 & 0.172 & 24.35 \\
\hline MOD13Q1 NDVI $_{\text {Med }}$ peak & 0.921 & 61.12 & 0.140 & 58.83 \\
\hline MOD09Q1 NDVI ${ }_{10}$ peak & 0.924 & 42.80 & 0.193 & 28.40 \\
\hline
\end{tabular}


Figure 4. Plots of biomass against VI data after differencing from baseline vegetation indices using three different approaches. In all cases, calculations are made after accounting for post-peak field collection data by using peak VI in place of the corresponding field data collection dates. Trend lines indicate the least squared estimate of the best linear fit to the data. Plots on the left side show relationships including all field data $(\mathrm{N}=51)$, and plots on the right show relationships after excluding Agua Fria data $(\mathrm{N}=40)$.
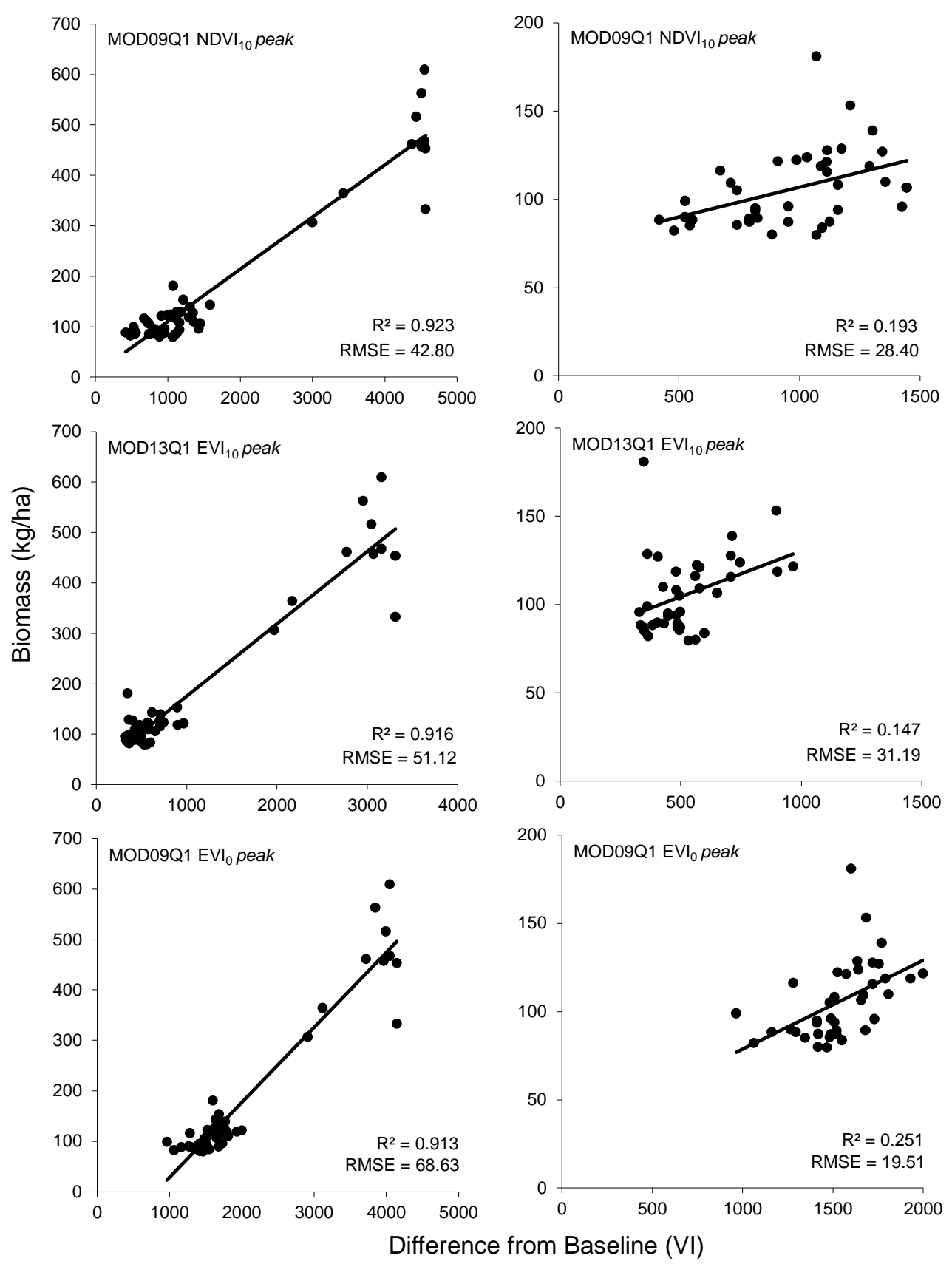

Of the MOD13Q1 data, the $\mathrm{NDVI}_{10}$ method after accounting for post-peak data collection provided the best model $(\mathrm{RMSE}=46.65)$, an improvement of $4.47 \mathrm{~kg} / \mathrm{ha}(9.6 \%)$ over the next best model (Table 2). Of the MOD13Q1 models, models using NDVI data performed slightly better on average $(3.28 \mathrm{~kg} / \mathrm{ha}-5.1 \%)$ than those using EVI data. 
For all models tested, models using the tenth percentile as a baseline from which to measure winter VI ( $\mathrm{VI}_{10}$ ) consistently provided the lowest RMSE error (an average of $77.78 \mathrm{~kg} / \mathrm{ha}$ ). This RMSE was an average of $18.52 \mathrm{~kg} / \mathrm{ha}(31.3 \%)$ lower than using the VI alone, and $33.01 \mathrm{~kg} / \mathrm{ha}(55.7 \%)$ lower than using the median of each period to establish a baseline.

Across all three data types, models that replaced VI values for post-peak field data collection with peak VI values had RMSEs that were $29.90 \mathrm{~kg} / \mathrm{ha}(48.6 \%)$ smaller than without correcting for field data collection dates. All models using 8-day data (MOD09Q1) had much higher errors than 16-day data for models not accounting for post-peak field data collection (an average of $30.55 \mathrm{~kg} / \mathrm{ha}, 38 \%$ higher), while after being corrected for post-peak field data collection the 8-day data had RMSE errors that are $4.12 \mathrm{~kg} / \mathrm{ha}(6.4 \%)$ lower than 16 -day data.

Of the five study areas, the Agua Fria area has substantially higher winter annual production than the other sites. Of the sites at Agua Fria, all but one of the sites was estimated at over $300 \mathrm{~kg} / \mathrm{ha}$, whereas the highest estimated biomass for all other sites was $181 \mathrm{~kg} / \mathrm{ha}$. If the Agua Fria sites are excluded from the analysis, the $\mathrm{R}^{2}$ values are substantially lower $(0.05-0.25)$, indicating a poorer fit across the reduced range of winter annual productivity. This is offset to some degree by lower RMSE values (19.51-104.20). While the patterns discernible from examining the RMSE errors from the more xeric subset of the data are not as clear (Figure 3(B)). There appears to be a slight improvement of EVI over NDVI data, with the 16-day $\mathrm{EVI}_{0}$ model after post-peak correction having an RMSE $7.16 \mathrm{~kg} / \mathrm{ha}$ (36.6\%) lower than 16 -day $\mathrm{NDVI}_{0}$ (Table 2 ).

\subsection{Winter Annual Biomass Images}

The production of images mapping winter annual biomass for all nine years of the study illustrated their potential usefulness in evaluating the spatial and temporal variations in winter annual biomass from year-to-year. Figure 5 illustrates this for Joshua Tree National Park. Large differences between high production years (e.g., 2004-2005) and low production years (2006-2007) can easily be discerned. While these are anecdotally confirmed, the spatial distribution of production is more difficult to establish, and more subtle distinctions are difficult to ascertain. For example, while a general pattern of productivity can be seen year to year, note the difference in the spatial pattern of productivity between 2003-2004 and 2007-2008. 2003-2004 followed the more typical pattern of higher production in the Western portion of the Park, whereas 2007-2008 had higher levels of production across the central portion of the Park.

Maps such as these could also prove useful for the prioritization of management activities. For example the high production season of 2004-2005 as seen in Figure 5 was followed by wildfires in the summer of 2005 in many parts of Joshua Tree National Park. While managers were certainly aware of high levels of winter annual production in the 2004-2005 season, maps such as these could help by highlighting areas of particularly high production or large amounts of change from previous years. 
Figure 5. Joshua Tree National Park peak winter annual above ground biomass, estimated as a function of 8-day MODIS NDVI over the 10th percentile from winter 2000-2001 through winter 2008-2009. The red line indicates the boundary of Joshua Tree National Park. Differences in both spatial and temporal distribution of winter annual biomass illustrate the value of using satellite-based maps of winter annual biomass. Black or grayscale areas represent less than $50 \mathrm{~kg} / \mathrm{ha}$ above ground biomass.
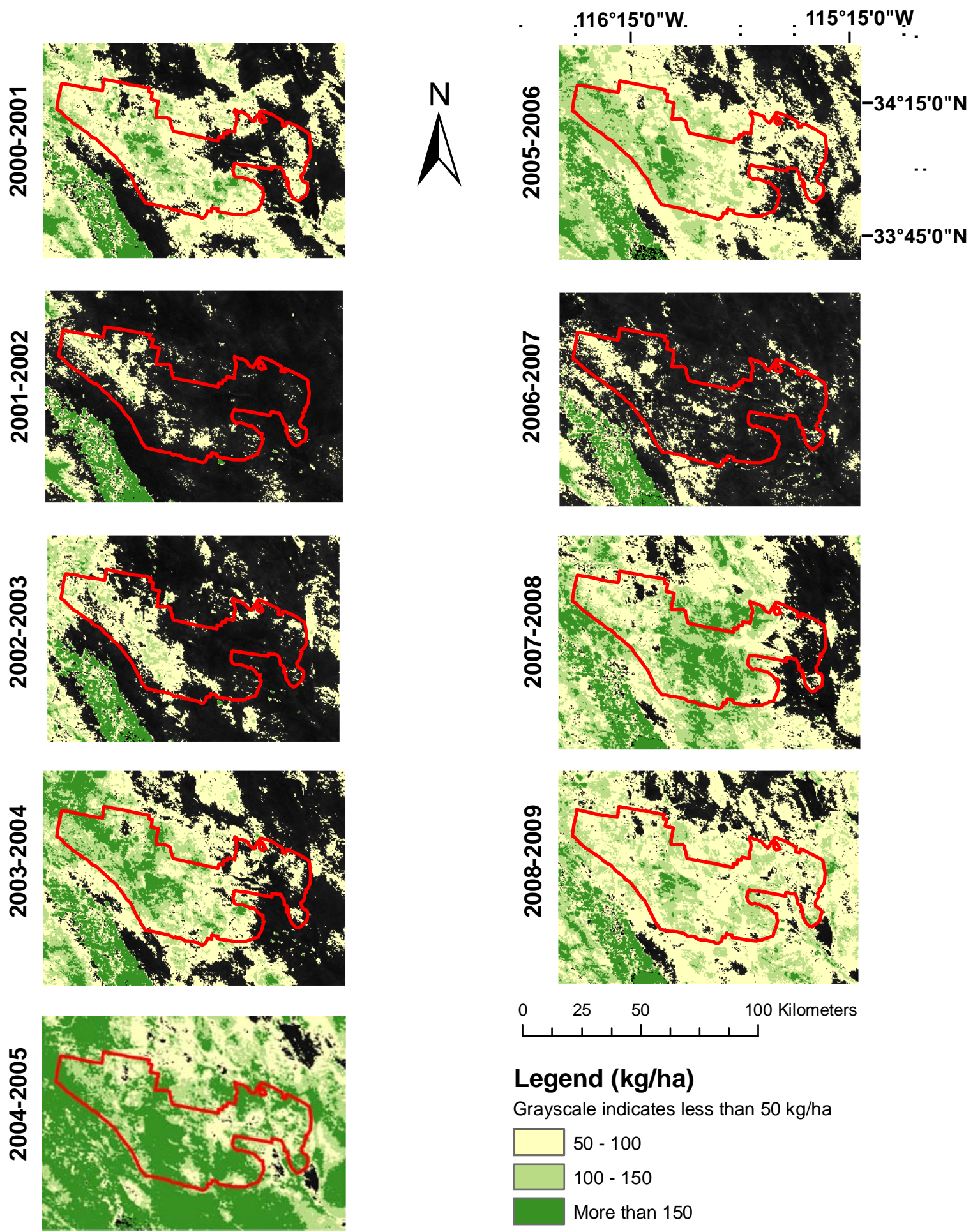

\section{Legend (kg/ha)}

Grayscale indicates less than $50 \mathrm{~kg} / \mathrm{ha}$

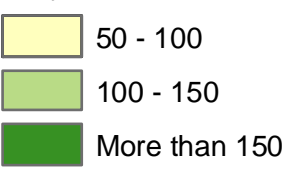




\section{Discussion}

The use of time-series remote sensing data for assessing winter annuals in arid environments using the methods described can be used as an important management tool. While the importance of monitoring winter annuals has been recognized e.g., [4,24,25], few operational tools have been put forward that allow landscape-level assessment of interannual variability in winter annual production. Wallace and Thomas [18] provide an important beginning of this work by proposing a method for assessing winter annual growth by making comparisons with particularly dry years; however their approach requires the selection of specific comparison dates, which may not be feasible for large areas exhibiting contrasting climate patterns across the region. Our approach resolves this issue by automatically selecting a comparison date appropriate to each pixel that can be used as a baseline from which to measure winter annual activity.

Assessment of the proposed models using goodness of fit metrics ( $\mathrm{R}^{2}$ and RMSE) reveals an important picture of the appropriate uses of these data for land management in arid environments. $\mathrm{R}^{2}$ values for the best models using the more arid subset of the sampled sites indicate that much of the variability in winter annual biomass remains unaccounted for $\left(\mathrm{R}^{2}=0.252\right)$. On the other hand, a RMSE of $19.51 \mathrm{~kg} / \mathrm{ha}$ for the same model indicates that changes on the order of $20 \mathrm{~kg} / \mathrm{ha}$ in a single year are likely to be adequately modeled using this approach. From a management perspective, this means that this approach is not likely to be of use for the detection of more subtle changes in production due to processes such as shifts in species composition or changes in levels of utilization from year to year. It does, however provide a useful tool for the more dramatic annual fluctuations that are indicative of species invasions or wildfire risk, which pose two of the greatest threats to desert ecosystems in the Southwest United States $[24,26]$. The relatively strong $\mathrm{R}^{2}$ after inclusion of the Agua Fria site $\left(\mathrm{R}^{2}=0.924\right)$ indicates that the model works well over a broad range of winter annual conditions, thus providing reasonable accuracy for large interannual shifts in production. Further investigation of sites with moderate productivity (200-400 kg/ha) could be done in order to improve the representation of sites across the range of potential winter annual conditions. Further, the extension of the recommended models to years of varying levels of productivity would benefit from additional research in subsequent years at the measured sites. While the included data span a large range of productivity, most of this range is realized across sites, and within-site inter-year variability may not follow the trend in production identified between sites.

Joshua Tree National Park provides a good example of the applicability of this model at a site with typically low winter annual production that changes dramatically when conditions are appropriate. The average estimated change in biomass between a year with low winter annual production (2001-2002) and a year with high production (2004-2005) was $84.54 \mathrm{~kg} / \mathrm{ha}$, with some pixels indicating changes of over $600 \mathrm{~kg} /$ ha (Figure 5). This kind of dramatic shift in production between years highlights the value of this tool for assessing changes in ecosystem function that may be indicative of the spread of invasive annuals or an increase in wildfire risk. Indeed, following the winter of 2004-2005, Joshua Tree experienced extensive wildfires at least in part due to the accumulation of winter annual biomass.

Ground-based assessments of biomass based on height and cover estimates for sub-plots within each of the 41 sites constitute a potential source of uncertainty for the biomass to VI relationships. Of necessity the estimates for this study included a variety of species of both forbs and grasses across a 
large area. Our results $\left(\mathrm{R}^{2}=0.699\right)$ are not dissimilar from others' results for mixed species estimates. Ahmed et al. [27] showed that ocular estimates of biomass for a mixture of species in northeastern Colorado yielded an $\mathrm{R}^{2}$ estimate of 0.686. Nafus et al. [28] found that assessing mixed species perennial grass biomass in the Sonoran Desert using height alone resulted in an $\mathrm{R}^{2}$ of 0.53 . Both studies showed, however, better relationships for single species models $\left(0.57<\mathrm{R}^{2}<0.92\right)$, and Nafus et al. showed much better results after including a measure of basal area $\left(0.82<\mathrm{R}^{2}<0.95\right)$. The inclusion of such refinements to local applications of the proposed models may result in more regionally appropriate applications of the use of time-series MODIS VI data for the assessment of winter annual biomass.

The evaluation of goodness of fit metrics for the 18 models considered above allows for inferences to be made regarding the attributes of MODIS VI data that best lend themselves to the assessment of winter annual biomass in southwestern North America, specifically in regards to the three research questions posed in the introduction. First, results do not indicate a dramatic difference between the use of NDVI and EVI vegetation indices. Goodness of fit metrics provide moderate evidence that NDVI performs better across the range of biomass, while EVI performs better on more xeric sites. This may be due to the greater dynamic range of NDVI across the range of vegetation biomass examined at these sites, and the inclusion of a soil background correction term included in the EVI. In the end, however, the differences between these two indices do not seem to be as important as the method used to select baseline VI values or the temporal resolution of the dataset.

The use of the tenth percentile across the time-series provided the best approach for determining a baseline from which to measure increases in winter VI for the estimation of winter annual biomass. This approach accounts for differences in VI values that are a function of differences in soil background, greenness due to evergreen vegetation, or woody structure on the site. By determining a base VI value winter annual biomass can be estimated using the increase in greenness from the established baseline.

The improvement of all techniques with the use of the VI data to determine the peak greenness and replace post-peak field collection dates with peak VI values argues for the importance of time-series data in evaluating winter annual biomass. Because of the opportunistic nature of winter annual growth in the Desert Southwest US, the selection of a single or several dates for use in estimating winter annuals is problematic. This approach allows one to determine the appropriate date of image data for each pixel. Since winter annual vegetation often greens up and senesces quickly, a mismatch of field sampling and peak vegetation greenness by a week or two may dramatically influence results.

Similarly, RMSE values for the models using MOD09Q1 data highlight the importance of the temporal resolution of the data. Models using the MOD09Q1 data without adjustment for post-peak field data collection dates show high RMSE values, likely due to the use of a compositing algorithm that is not optimized for use with VIs. In spite of this, after correcting for post-peak collection dates by using peak VI values instead of data coinciding with post-peak field data collection dates, the models which utilize MOD09Q1 data have the lowest error rates. This may be due to the 8-day temporal resolution of the MOD09 data, allowing for a finer scale determination of peak greenness, and thus a more accurate correction of post-peak data collection dates.

From the evidence gathered by examining the results of these 18 models, it is apparent that a more appropriate data product for the detection and monitoring of winter annuals in the Desert Southwest would be a VI product composited every 8 days according to the MOD13 compositing algorithm, and 
using the peak VI value to establish winter annual production for the season. Such a product is not currently available at the LP DAAC. For Collection 5 MODIS data, the MOD13Q1 and MYD13Q1 (Aqua-borne MODIS data collected in the afternoon) have been phased such that each product provides a 16-day composite staggered in such a way that one is available every 8 days. This may also provide an alternative approach, although sensor based differences may make it challenging to use the two products in a single time-series.

\section{Conclusions}

Our results indicate that time-series satellite based vegetation index data provide an important tool for addressing the challenges of assessing winter annual biomass in the Mojave and Sonoran deserts. We describe a new approach for estimating winter annual biomass across a large range of semi-arid conditions across the Southwest US by evaluating the time-series to establish the minimum vegetation state of each pixel and comparing it to the winter peak. This study highlights the fact that compositing techniques, differences in vegetation index algorithms, and temporal resolution are all important considerations when evaluating remotely sensed estimates of winter annual biomass. Further, our work highlights the importance of time-series satellite-based vegetation data in matching field-based measures of senescent vegetation biomass to satellite-based estimates of peak greenness using vegetation indices.

Our results indicate that an 8-day vegetation index product composited using maximum vegetation index values and minimum view angle criteria would provide the most appropriate MODIS product for assessing winter annual biomass in the Southwest. While such a product may improve on the results presented here, existing products still result in a valuable technique that provides a good tool for detecting deviations in winter annual production which may lead to increases in wildland fire, or indicate increases in the presence of invasive annual plants. The described approach also provides a good basis from which to evaluate variability in winter annual production over time, which predicates an ability to predict the likelihood of high or low production winters and allows for further evaluation of the relationship between climate in the Desert Southwest US and winter productivity. Future efforts could refine this approach by collecting additional field observations across a range of semi-arid winter annual production in desert ecosystems in the Southwest US.

\section{Acknowledgments}

We are grateful for various agency personnel for their assistance in finding and accessing field sites, including Alice Miller, Jane Cipra, and Jason van Warmerdam from the National Park Service, Darrell Tersey and Lori Young from the Bureau of Land Management, and Joanne Roberts with Arizona State Parks. We are also indebted to a number of individuals who participated in field data collection, including Brett Blum, Nancy Casady, Sara Chavarria, Jen Davison, Murad Ishankuliev, Jahan Kariyeva, Raul Romo, and Abd salam El Vilaly. The authors are also grateful for comments from Dennis Dye, Todd Hawbaker, and three anonymous reviewers which led to a much improved manuscript. This research project "Remote Sensing of the Phenology of Desert Annuals" was funded

by the US Geological Survey-Colorado Plateau Cooperative Ecosystem Studies Unit (project\# 08HQPA0016). 


\section{References}

1. Hazard, L.C.; Shemanski, D.R.; Nagy, K.A. Nutritional quality of natural foods of juvenile desert (gopherus agassizii): Energy, nitrogen, and fiber digestibility. J. Herpetol. 2009, 43, 38-48.

2. USFWS. Desert Tortoise (Mojave Population) Recovery Plan; US Fish and Wildlife Service: Portland, OR, USA, 1994; p. 73.

3. Alford, E.J.; Brock, J.H.; Gottfried, G.J. Effects of Fire on Sonoran Desert Plant Communities; RMRS-P-36; Rocky Mountain Research Station, USDA Forest Service: Fort Collins, CO, USA, 2005; pp. 451-454.

4. Brooks, M.L.; D’Antonio, C.M.; Richardson, D.M.; Grace, J.B.; Keeley, J.E.; DiTomaso, J.M.; Hobbs, R.J.; Pellant, M.; Pyke, D. Effects of invasive alien plants on fire regimes. Bioscience 2004, 54, 677-688.

5. Rogers, G.F. Mortality of burned cereus giganteus. Ecology 1985, 66, 630-632.

6. Helm, P.J.; Breed, C.S. Instrumented Field Studies of Sediment Transport by Wind. In Desert Winds: Monitoring Wind-Related Surface Processes in Arizona, New Mexico, and California; Breed, C.S., Reheis, M.C., Eds.; United States Government Printing Office: Washington, DC, USA, 1999; pp. 31-50.

7. Brooks, M.L.; Berry, K.H. Dominance and environmental correlates of alien annual plants in the Mojave Desert, USA. J. Arid Environ. 2006, 67, 100-124.

8. Brooks, M.L.; Matchett, J.R. Spatial and temporal patterns of wildfires in the Mojave Desert, 1980-2004. J. Arid Environ. 2006, 67, 148-164.

9. Bowers, J.E. El nino and displays of spring-flowering annuals in the Mojave and Sonoran Deserts. J. Torrey Bot. Soc. 2005, 132, 38-49.

10. Wylie, B.K.; Denda, I.; Pieper, R.D.; Harrington, J.A.; Reed, B.C.; Southward, G.M. Satellite-based herbaceous biomass estimates in the pastoral zone of Niger. J. Range Manage. 1995, 48, 159-164.

11. Pickup, G.; Bastin, G.N. Spatial distribution of cattle in arid rangelands as detected by patterns of change in vegetation cover. J. Appl. Ecol. 1997, 34, 657-667.

12. Elmore, A.J.; Mustard, J.F.; Manning, S.J.; Lobell, D.B. Quantifying vegetation change in semiarid environments: Precision and accuracy of spectral mixture analysis and the normalized difference vegetation index. Remote Sens. Environ. 2000, 73, 87-102.

13. Rowe, J. Concepts of Fire Effects on Plant Individuals and Species. In The Role of Fire in Northern Circumpolar Ecosystems; Wein, R.W., MacLean, D.A., Eds.; Wiley: Chichester, UK, 1983; pp. 135-154.

14. Goward, S.N.; Tucker, C.J.; Dye, D.G. North-American vegetation patterns observed with the NOAA-7 advanced very high-resolution radiometer. Vegetatio 1985, 64, 3-14.

15. Prince, S.D.; Goetz, S.J.; Goward, S.N. Monitoring primary production from earth observing satellites. Water Air Soil Pollution 1995, 82, 509-522.

16. Zhang, X.Y.; Friedl, M.A.; Schaaf, C.B.; Strahler, A.H.; Hodges, J.C.F.; Gao, F.; Reed, B.C.; Huete, A. Monitoring vegetation phenology using MODIS. Remote Sens. Environ. 2003, 84, 471-475. 
17. Van Leeuwen, W.J.D.; Orr, B.J.; Marsh, S.E.; Herrmann, S.M. Multi-sensor NDVI data continuity: Uncertainties and implications for vegetation monitoring applications. Remote Sens. Environ. 2006, 100, 67-81.

18. Wallace, C.S.A.; Thomas, K.A. An annual plant growth proxy in the Mojave Desert using MODIS-EVI data. Sensors 2008, 8, 7792-7808.

19. Bonham, C.D. Measurements for Terrestrial Vegetation; John Wiley and Sons: New York, NY, USA, 1989; p. 338.

20. Huete, A.; Didan, K.; Miura, T.; Rodriguez, E.P.; Gao, X.; Ferreira, L.G. Overview of the radiometric and biophysical performance of the MODIS vegetation indices. Remote Sens. Environ. 2002, 83, 195-213.

21. Vermote, E.F.; Kotchenova, S.Y. MOD09 (Surface Reflectance) User's Guide; MODIS Land Surface Reflectance Science Computing Facility: College Park, MD, USA, 2008.

22. Jonsson, P.; Eklundh, L. Timesat-A program for analyzing time-series of satellite sensor data. Comput. Geosci. 2004, 30, 833-845.

23. Huete, A.R.; Liu, H.Q. An error and sensitivity analysis of the atmospheric-correcting and soil-correcting variants of the NDVI for the MODIS-EOS. IEEE Trans. Geosci. Remote Sens. 1994, 32, 897-905.

24. McLaughlin, S.P.; Bowers, J.E. Effects of wildfire on a Sonoran Desert plant community. Ecology 1982, 63, 246-248.

25. Bowers, M.A. Precipitation and the relative abundances of desert winter annuals-A 6-year study in the northern Mohave Desert. J. Arid Environ. 1987, 12, 141-149.

26. Brooks, M.L. Competition between alien annual grasses and native annual plants in the Mojave Desert. Am. Midl. Nat. 2000, 144, 92-108.

27. Ahmed, J.; Bonham, C.D.; Laycock, W.A. Comparison of techniques used for adjusting biomass estimates by double sampling. J. Range Manage. 1983, 36, 217-221.

28. Nafus, A.M.; McClaran, M.P.; Archer, S.R.; Throop, H.L. Multispecies allometric models predict grass biomass in semidesert rangeland. Rangeland Ecol. Manage. 2009, 62, 68-72.

(C) 2013 by the authors; licensee MDPI, Basel, Switzerland. This article is an open access article distributed under the terms and conditions of the Creative Commons Attribution license (http://creativecommons.org/licenses/by/3.0/). 